American Journal of Applied Sciences 5 (8): 952-958, 2008

ISSN 1546-9239

(C) 2008 Science Publications

\title{
An Aggregation Approach for Group Multicriteria Assignment
}

\author{
George Rigopoulos, John Psarras and Dimitrios Th. Askounis \\ School of Electrical and Computer Engineering, National Technical University of Athens, \\ 9 Iroon Polytechneiou Str, 15773, Athens, Greece
}

\begin{abstract}
We presented an aggregation approach for group multicriteria assignment decisions, where group members express their preferences on problem parameters in numeric format. Individual preferences are aggregated by WOWA operator following the majority concept and a group parameter set is derived that is used as input for the classification algorithm. In addition, we present a numeric example of the approach, demonstrating its applicability. The methodology has been applied to classification problems in business environment, with sufficient results depicting its validity for such problems.
\end{abstract}

Key words: Group decision making, multicriteria analysis, classification

\section{INTRODUCTION}

Multicriteria analysis has been utilized to assist group decision making in a variety of problems, resulting in numerous methodologies and group decision support systems $[1,3,4,5,8,12,14,16,17,18,21,22,23,24$, ${ }^{25,28]}$. Matsatsinis and Samaras ${ }^{[20]}$ present an extensive review of such approaches, which clearly indicates that multicriteria analysis is a valid way to handle the inherent complexity of group decisions and structure such problems. It provides a structured way for problem formulation and guides members to understand requirements effectively and express their preferences reflecting their individual decision model.

Modelling a group decision problem in multicriteria setting can be formulated under two major approaches:

- In the first approach, individual multicriteria models are developed, which capture individuals' preferences. Each group member formulates a multicriteria problem defining the parameters according to his preferences and solves the problem getting an individual solution set. Next, the separate solutions are aggregated by aggregation operators providing thus the group solution.

- In the second approach, a multicriteria model is developed for the entire team. Each group member provides a set of parameters that are aggregated by appropriate operators, providing finally a group parameter set. Upon this set the muticriteria method is applied and the solution expresses group preference.

Each approach poses both positive and negative aspects depending on the aggregation operation, which is followed. An issue that arises in such problems is the appropriate aggregation of values in a way to express group preferences. The aggregation problem has been studied in several works $[2,6,7,15,19,29]$ either in multicriteria problems or general group problems.

The objective of our work is to present an aggregation procedure for group decision problems in multicriteria classification decisions. The classification problem refers to the assignment of a set of actions in a number of categories and it can be defined in group setting as:

Having a set of actions (e.g. projects, people, numbers, etc.), a set of categories and a set of evaluation criteria, assign actions to categories with respect to their score on the evaluation criteria according to group members' preferences.

Our approach follows the second direction, where we utilize WOWA operator for the aggregation of individual preferences calculating an aggregated set of group parameters, which is used as input for the classification algorithm. The multicriteria classification algorithm we use is based on the concept of inclusion/exclusion of an action with respect to a category. In order to apply the entire procedure, initially a set of parameters is proposed to the group by group facilitator. Next, each group member evaluates the proposed parameter set and expresses his preferences in numeric format. Individual preferences are then

Corresponding Author: George Rigopoulos, School of Electrical and Computer Engineering, 
aggregated by WOWA operator and a group parameter set is produced. Classification algorithm is finally applied, using the group parameter set, for the classification of actions and group members evaluate derived results. In case of low level of acceptance, parameters are redefined and aggregation phase is repeated.

In this study we focus on the aggregation procedure of group preferences, presenting the proposed approach, as well as a numeric example, which demonstrates its application to real world problems. Initially, we present background information on OWA and WOWA operators, as well as a brief overview of the multicriteria classification algorithm. The aggregation approach is then presented continuing with an example, which demonstrates methodology's applicability. Finally, we conclude summarizing key findings.

\section{MATERIALS AND METHODS}

OWA operator (Ordered Weighted Averaging Operator): OWA operator was initially introduced by Yager $^{[29]}$ and was further developed and discussed in

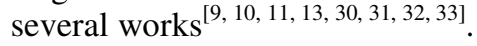

Definition: An OWA operator of dimension $n$ is a mapping function $\phi: \Re^{\mathrm{n}} \rightarrow \mathfrak{R}$, which has a weighting vector associated with it $\mathrm{W}=\left(\mathrm{w}_{1}, \ldots, \mathrm{w}_{\mathrm{n}}\right)$ such as

$$
\mathrm{w}_{\mathrm{i}} \in[0,1] \text {, and } \sum_{\mathrm{i}=1}^{\mathrm{n}} \mathrm{w}_{\mathrm{i}}=1
$$

and aggregates a set of values $\left\{\mathrm{p}_{1}, \ldots, \mathrm{p}_{\mathrm{n}}\right\}$ according to the following expression

$$
\phi_{\mathrm{w}}\left(\mathrm{p}_{1}, \ldots, \mathrm{p}_{\mathrm{n}}\right)=\sum_{\mathrm{i}=1}^{\mathrm{n}} \mathrm{w}_{\mathrm{i}} \times \mathrm{p}_{\sigma(\mathrm{i})}
$$

where, $\sigma:\{1, \ldots, \mathrm{n}\} \rightarrow\{1, \ldots \mathrm{n}\}$ is a permutation of set $\left\{p_{1}, \ldots, p_{n}\right\}$ such as $p_{\sigma(i)} \geq p_{\sigma(i+1)}, \forall i=1, \ldots$ n-1, (e.g., $p_{\sigma(i)}$ is the $\mathrm{i}$-highest value in set $\left\{\mathrm{p}_{1}, \ldots, \mathrm{p}_{\mathrm{n}}\right\}$.

A basic property of OWA is the reordering of arguments according to their values, which associates a weight to particular positions in the ordered set of values and not to the values. OWA operators are commutative, monotonic and idempotent, following the basic properties of averaging operators.

Weight vector definition is a basic issue for the OWA operator. Yager proposes two methods for their estimation ${ }^{[29]}$. The first approach uses a kind of training approach using some training data, while the second one assigns semantics on the weights. Following the second approach, weights can express the concept of fuzzy majority on the aggregation of the values with $\mathrm{OWA}^{[34]}$.
In this approach weights can be obtained by using a functional form of linguistic quantifiers. In this case a quantifier is defined as a function Q: $[0.1] \rightarrow[0,1]$ where $\mathrm{Q}(0)=0, \mathrm{Q}(1)=1$, and $\mathrm{Q}(\mathrm{x}) \geq \mathrm{q}(\mathrm{y})$ for $\mathrm{x} \geq \mathrm{y}$. For a given value $x \in[0,1]$, the $Q(x)$ is the degree to which $\mathrm{x}$ satisfies the fuzzy concept being represented by the quantifier.

Based on function Q the OWA weight vector is given by the following expression

$$
\mathrm{w}_{\mathrm{i}}=\mathrm{Q}\left(\frac{\mathrm{i}}{\mathrm{n}}\right)-\mathrm{Q}\left(\frac{\mathrm{i}-1}{\mathrm{n}}\right), \mathrm{i}=1, \ldots, \mathrm{n} .
$$

Following this approach, the quantifier determines the weighting vector according to the semantics associated with the operator from function Q. Zadeh ${ }^{[34]}$ defined membership function of quantifier $Q$ by the following expression

$$
Q(r)=\left\{\begin{array}{lr}
0, & \text { if } r<a \\
\frac{(r-a)}{b-a}, & \text { if } a £ r £ b \\
1, & \text { if } r>b
\end{array}\right.
$$

with $a, b, r \in[0,1]$.

The most common quantifiers used are most, at least half, as many as possible with parameters $(\mathrm{a}, \mathrm{b})$ equal to $(0.3,0.8),(0.05),(0.5,1)$, respectively. For example the fuzzy majority concept can be expressed by using quantifier $\mathrm{Q}$ most with values $(a, b)=(0.3,0.8)$ for the calculation of OWA weights.

The fuzzy majority approach with OWA aggregation has been utilized as is or with variations on group decisions ${ }^{[13]}$, where the objective was the maximization of group consensus, since this approach is more appropriate than simple averaging operators.

WOWA operator (Weighted OWA): WOWA operator was introduced by Torra ${ }^{[26,27]}$ in order to extend OWA based aggregation in a way to consider weights of sources in addition to weights of values.

Definition: A WOWA operator of dimension $\mathrm{n}$ is a mapping function $\phi_{\text {wowa }}: \mathfrak{R}^{\mathrm{n}} \rightarrow \mathfrak{R}$, which has two weight vectors associated with it, $\mathrm{W}=\left(\mathrm{w}_{1}, \ldots, \mathrm{w}_{\mathrm{n}}\right)$ with

$$
\mathrm{w}_{\mathrm{i}} \hat{\mathrm{I}}[0,1], \sum_{\mathrm{i}=1}^{\mathrm{n}} \mathrm{w}_{\mathrm{i}}=1,
$$

(which expresses the values importance in analogy to OWA weights $)$ and $\mathrm{B}=\left(\beta_{1}, \ldots, \beta_{\mathrm{n}}\right)$ with

$$
\beta_{\mathrm{i}} \hat{I}[0,1], \sum_{\mathrm{i}=1}^{\mathrm{n}} \beta_{\mathrm{i}}=1,
$$


(which expresses the importance of sources in analogy to a weighted average operator) and aggregates a set of values $\left\{\mathrm{p}_{1}, \ldots, \mathrm{p}_{\mathrm{n}}\right\}$ with the following expression

$$
\phi_{\text {WOWA }}\left(p_{1}, \ldots, p_{n}\right)=\sum_{i=1}^{n} \omega_{i} \times p_{\sigma(i)}
$$

where, $\sigma:\{1, \ldots, n\} \rightarrow\{1, \ldots n\}$ is a permutation of set $\left\{\mathrm{p}_{1}, \ldots, \mathrm{p}_{\mathrm{n}}\right\} \quad$ such that $\mathrm{p}_{\sigma(\mathrm{i})} \geq \mathrm{p}_{\sigma(\mathrm{i}+1)}, \forall \mathrm{i}=1, \ldots \mathrm{n}-1$, (e.g., $\mathrm{p}_{\sigma(\mathrm{i})}$ is the $\mathrm{i}$-highest value in set $\left\{\mathrm{p}_{1}, \ldots, \mathrm{p}_{\mathrm{n}}\right\}$ and $\omega=\left(\omega_{1}, \ldots, \omega_{n}\right)$ and

$$
\omega_{i} \hat{I}[0,1], \sum_{i=1}^{n} \omega_{i}=1
$$

is the weight vector of WOWA operator.

Weights $\omega=\left(\omega_{1}, \ldots, \omega_{n}\right)$ are defined as:

$$
\omega_{\mathrm{i}}=\mathrm{w} *\left(\sum_{\mathrm{j} f \mathrm{i}} \beta_{\sigma(\mathrm{j})}\right)-\mathrm{w} *\left(\sum_{\mathrm{j}<\mathrm{i}} \beta_{\sigma(\mathrm{j})}\right),
$$

where, $\mathrm{w}^{*}$ is a monotone increasing function which interpolates points $\left(\mathrm{i} / \mathrm{n}, \sum_{\mathrm{j} \in \mathrm{i}} \mathrm{w}_{\mathrm{j}}\right)$ with the point $(0,0)$.

Calculation of $\mathrm{w}^{*}$ can be executed a) either from direct definition of function $\mathrm{w}^{*}$, or $\mathrm{b}$ ) from the definition of the vector $\mathrm{W}=\left(\mathrm{w}_{1}, \ldots, \mathrm{w}_{\mathrm{n}}\right)$ initially and calculation of the interpolation function $\mathrm{w}^{*}$ next.

Following the second approach, for the evaluation of the function $\mathrm{W}^{*}$ from the weight vector $\mathrm{W}=$ $\left(\mathrm{w}_{1}, \ldots, \mathrm{w}_{\mathrm{n}}\right)$ an interpolation method is required. From available methods the one to be used, has to define a monotonous and bounded function (e.g., polynomial) when input data are monotonous and bounded. WOWA operator can be considered as generalization of weighted mean and OWA operators, since for equivalent sources' weights it coincides with OWA, while for equivalent values' weights it coincides with weighted mean.

From the analysis of relevant works we derive that WOWA operator is quite efficient for the aggregation of the individuals values in group setting, since it allows aggregation of values considering members' importance and the definition of zones of different importance which express variations of majority values.

Multicriteria classification algorithm: Inclusion/ exclusion from a category is determined by evaluating the fuzzy inclusion degree of the action for the specific category, following the concordance/non-discordance concepts as used in ELECTRE III method. Categories are defined by an entrance threshold, which can be considered as the least typical representative action that satisfies the inclusion requirements. The objective of the algorithm is to classify actions to categories in a way to consider inclusion/exclusion concept.

Fuzzy inclusion degree: The inclusion/exclusion concept defines at what degree an action can be included in a category or excluded from it. In order to utilize this concept for classification of actions, we define the fuzzy inclusion relation. Fuzzy inclusion relation $\mathrm{P}(\mathrm{a}, \mathrm{b})$ is defined as a binary relation between an action $a_{i}$ and a category threshold $b^{h}$. According to the concept of inclusion/exclusion and considering category thresholds, an action $\mathrm{a}_{\mathrm{i}}$ is preferred over a threshold $b^{\mathrm{h}}$ (and can be thus included in the category $\mathrm{C}^{\mathrm{h}}$ ) iff there is a majority of criteria supporting preference of action $a_{i}$ over threshold $b^{\mathrm{h}}$ and there is no strong opposition to this. In order to evaluate the relation $\mathrm{P}(\mathrm{a}, \mathrm{b})$ we utilize concordance/non-discordance principle, defining appropriate indexes as follows:

A criterion is said to be concordant if it expresses agreement about classification of action $a_{i}$ to a class $C^{\mathrm{h}}$. For the evaluation of concordance per criterion, we define the partial inclusion index for action $a_{i}$ and criterion $g_{j}$ as $C_{j}\left(a_{i}, b^{h}\right)$. In order to overcome imprecision in definition of data, we define two discrimination thresholds $\mathrm{q}\left(\mathrm{g}_{\mathrm{j}}\right)$ and $\mathrm{p}\left(\mathrm{g}_{\mathrm{j}}\right)$ for each criterion, resulting in three areas of values as follows:

$$
\begin{aligned}
& \mathrm{C}_{j}\left(a_{i}, b^{h}\right)=\left\{\begin{array}{c}
0 \\
\frac{g_{j}\left(a_{i}\right)-g_{j}\left(b^{h}\right)-q\left(g_{j}\right)}{p\left(g_{j}\right)-q\left(g_{j}\right)} \\
1
\end{array}\right. \\
& \text { for }\left[g_{j}\left(a_{i}\right) \leq g_{j}\left(b^{h}\right)+q\left(g_{j}\right)\right], \\
& {\left[g_{j}\left(b^{h}\right)+q\left(g_{j}\right) \leq g_{j}\left(a_{i}\right) \leq g_{j}\left(b^{h}\right)+p\left(g_{j}\right)\right],} \\
& {\left[g_{j}\left(a_{i}\right) \geq g_{j}\left(b^{h}\right)+p\left(g_{j}\right)\right]}
\end{aligned}
$$

For the evaluation of concordance degree for all criteria, we define the comprehensive inclusion index for action $\mathrm{a}_{\mathrm{i}}$ as:

$$
\mathrm{C}\left(\mathrm{a}_{\mathrm{i}}, \mathrm{b}^{\mathrm{h}}\right)=\sum_{\mathrm{j}=1}^{\mathrm{m}} \mathrm{w}_{\mathrm{j}} * \mathrm{C}_{\mathrm{j}}\left(\mathrm{a}_{\mathrm{i}}, \mathrm{b}^{\mathrm{h}}\right)
$$

where, $w_{j}$ is the importance weight of criterion $g_{j}$.

In some cases a criterion can express negative judgment about classification of action $\mathrm{a}_{\mathrm{i}}$ to a class $\mathrm{C}^{\mathrm{h}}$. More specifically, a criterion $g_{j}$ can express a significant opposition to action's $\mathrm{a}_{\mathrm{i}}$ preference (or inclusion) over threshold $b^{\mathrm{h}}$. In this case the criterion is discordant with the inclusion relation between action 
$a_{i}$ and threshold $b^{h}$. We define a discordance index $D_{j}\left(a_{i}, b^{h}\right)$ for every criterion, in order to measure the discordance degree. To handle imprecision, we define a veto threshold $\mathrm{v}\left(\mathrm{g}_{\mathrm{j}}\right)$ for each criterion as the minimum value which is incompatible with the assertion that the criterion is discordant with the inclusion relation, resulting in three areas of values as follows:

$$
\begin{aligned}
& D_{j}\left(a_{i}, b^{h}\right)=\left\{\begin{array}{c}
0 \\
\frac{g_{j}\left(a_{i}\right)-g_{j}\left(b^{h}\right)-p\left(g_{j}\right)}{v\left(g_{j}\right)-p\left(g_{j}\right)} \\
1
\end{array}\right. \\
& \text { for }\left[g_{j}\left(a_{i}\right) \leq g_{j}\left(b^{h}\right)+p\left(g_{j}\right)\right], \\
& g_{j}\left(b^{h}\right)+p\left(g_{j}\right) \leq g_{j}\left(a_{i}\right) \leq g_{j}\left(b^{h}\right)+v\left(g_{j}\right) \\
& g_{j}\left(a_{i}\right) \geq g_{j}\left(b^{h}\right)+v\left(g_{j}\right)
\end{aligned}
$$

Utilizing the concordance/non-discordance principles we define the comprehensive fuzzy inclusion relation aggregating the inclusion relations Eq. 2 weakened by discordance Eq. 3 as:

$$
P\left(a_{i}, b^{h}\right)=C\left(a_{i}, b^{h}\right) * \prod_{j=1}^{m}\left(\frac{1-D_{j}\left(a_{i}, b^{h}\right)}{1-C\left(a_{i}, b^{h}\right)}\right) .
$$

Finally, we define the fuzzy inclusion degree as $\gamma\left(\mathrm{a}_{\mathrm{i}}, \mathrm{C}^{\mathrm{h}}\right)=\mathrm{P}\left(\mathrm{a}_{\mathrm{i}}, \mathrm{b}^{\mathrm{h}}\right)$.

Required parameters: In order to solve group classification problems using the fuzzy inclusion degree as defined above requires the definition of a set of appropriate parameters. In the general case where a facilitator guides the process initiating parameters, the following parameters are required:

- Members: Facilitator defines group members $M=\left\{m_{1}, m_{2}, \ldots m_{n}\right\}$ and assigns importance weights $B=\left\{\beta_{1}, \ldots, \beta_{j}\right\}$ to each.

- Evaluation criteria: Facilitator defines a set of evaluation criteria $\mathrm{F}=\left\{\mathrm{g}_{1}, \mathrm{~g}_{2}, \ldots \mathrm{g}_{\mathrm{n}}\right\}$ according to problem requirements and defines initial criteria weights.

- Categories: Facilitator defines a set of categories $\Omega=\left\{\mathrm{C}^{1}, \mathrm{C}^{2}, \ldots, \mathrm{C}^{\mathrm{h}}\right\}$ for the classification of actions. Categories are defined by their entrance thresholds $b^{\mathrm{h}}$ and their scores to evaluation criteria $\mathrm{g}_{\mathrm{j}}\left(\mathrm{b}^{\mathrm{h}}\right)$.

- Actions: Facilitator defines a set of actions $A=\left\{a_{1}, a_{2}, \ldots, a_{m}\right\}$ for classification, which are defined by their performance on the evaluation criteria $\forall \mathrm{a}, \mathrm{g}(\mathrm{a})=\left(\mathrm{g}_{1}(\mathrm{a}), \mathrm{g}_{2}(\mathrm{a}), \ldots, \mathrm{g}_{\mathrm{n}}(\mathrm{a})\right)$.
For each criterion facilitator defines initial preference, indifference and veto thresholds.

After the initiation of parameters, facilitator informs members asking them to submit their preferences.

Aggregation of individuals' parameter sets: In this phase group members express their preferences on the proposed parameter set. Member preferences are expressed or converted in numeric values. For the aggregation of values we utilize the WOWA Operator $^{[26,27]}$. Aggregation of member preferences is executed for the following parameters:

- Criteria: Group members express their acceptance on each proposed criterion and their preferred weight in numeric value.

- Categories: Group members express their acceptance on each category definition and submit their preferences on category thresholds in numeric value.

- Alternatives: Group members express their acceptance on alternatives' performance or submit their preference in numeric value.

- Thresholds: Group members express their preference on indifference, preference and veto thresholds in numeric format.

\section{RESULTS AND DISCUSSION}

In the following we demonstrate the proposed aggregation approach on sample data, focusing on the aggregation of group preferences. We consider a classification problem with the following initial parameters:

- A group of seven members $\mathrm{M}=\left\{\mathrm{m}_{\mathrm{j}}\right\}, \mathrm{j}=1, \ldots 7$ as decision makers and corresponding importance weights $\mathrm{B}=\left\{\beta_{1}, \ldots, \beta_{\mathrm{j}}\right\}=\{0.2,0.2,0.1,0.1,0.1$, $0.2,0.1\}$,

- A set of evaluation criteria $\mathrm{G}=\left\{\mathrm{g}_{\mathrm{i}}\right\}, \mathrm{i}=1, \ldots 8$,

- A set of categories $\mathrm{C}=\left\{\mathrm{C}^{\mathrm{i}}\right\}, \mathrm{i}=1, \ldots 4$ for the classification of actions,

- A set of alternatives $\mathrm{A}=\left\{\mathrm{a}_{\mathrm{i}}\right\}, \mathrm{i}=1, \ldots, 6$ for classification,

The objective is to classify the alternatives $\mathrm{A}=\left\{\mathrm{a}_{\mathrm{i}}\right\}, \mathrm{i}=1, \ldots, 6$ in appropriate categories $\mathrm{C}=\left\{\mathrm{C}^{\mathrm{i}}\right\}$, $\mathrm{i}=1, \ldots 4$. The aggregation process is as follows:

Step 1: We define, values to be aggregated $\left\{\mathrm{p}_{1}, \ldots, \mathrm{p}_{\mathrm{n}}\right\}$ as given by members and members' weights, which are 
$\mathrm{B}=\left\{\beta_{1}, \ldots, \beta_{\mathrm{j}}\right\}=\{0.2,0.2,0.1,0.1,0.1,0.2,0.1\}$, by definition.

Step 2 : Calculate associated WOWA weights $\mathrm{W}=\left(\mathrm{w}_{1}, \ldots, \mathrm{w}_{\mathrm{n}}\right)$ by means of OWA. For the calculation we consider the fuzzy majority concept and use the values $(a, b)=(0.3,0.8)$ representing the most value for the quantifier

$$
Q(r)=\left\{\begin{array}{lr}
0, & \text { if } r<a \\
\frac{(r-a)}{b-a}, & \text { if } a £ r £ b \\
1, & \text { if } r>b
\end{array}\right.
$$

and evaluate the weights of the OWA operator from the expression $\left.\mathrm{w}_{\mathrm{i}}=\mathrm{Q}(\mathrm{i} / \mathrm{n})-\mathrm{Q}(1-1) / \mathrm{n}\right), \mathrm{i}=1, \ldots, \mathrm{n}$.

Step 3: Following an approach proposed by Torra ${ }^{[26,27]}$ calculate WOWA weights $\omega=\left(\omega_{1}, \ldots, \omega_{n}\right)$. Initially we calculate the set of points that will be connected. This set is defined as

$$
\mathrm{S}=\left\{\left(\mathrm{i} / \mathrm{n}, \sum_{\mathrm{j} \leq \mathrm{i}} \mathrm{w}_{\mathrm{j}}\right) \mid \mathrm{i}=1, \ldots, \mathrm{n}\right\} \cup\{(0,0)\}
$$

Next the set of points is interpolated and function $\mathrm{w}^{*}$ is calculated.

Step 4: With respect to the sets of weights $\omega=\left(\omega_{1}, \ldots, \omega_{n}\right)$ aggregate the set of values $\left\{p_{1}, \ldots, p_{n}\right\}$ as

$$
\phi_{\text {WowA }}\left(\mathrm{p}_{1}, \ldots, \mathrm{p}_{\mathrm{n}}\right)=\sum_{\mathrm{i}=1}^{\mathrm{n}} \omega_{\mathrm{i}} \times \mathrm{p}_{\sigma(\mathrm{i})} .
$$

Illustrating example: In the following we present the aggregation as applied to criteria acceptance and criteria weights, since the same procedure is applied to the rest of values.

Step 1: Initially, each member $m_{j}$ expresses his opinion indicating acceptance level in a linguistic scale \{Extremely High, High, Medium, Low, Extremely Low , on the set of criteria These values are converted to numeric ones from 5 to 1 as below.

$$
\left[\mathrm{g}_{\mathrm{ij}}\right]=\left[\begin{array}{lllllll}
5 & 5 & 4 & 5 & 4 & 4 & 4 \\
4 & 2 & 3 & 1 & 2 & 1 & 2 \\
5 & 5 & 3 & 4 & 5 & 3 & 4 \\
3 & 5 & 3 & 4 & 5 & 4 & 5 \\
2 & 4 & 3 & 4 & 5 & 5 & 4 \\
4 & 4 & 5 & 4 & 5 & 5 & 5 \\
5 & 4 & 5 & 5 & 5 & 5 & 5 \\
1 & 3 & 2 & 3 & 1 & 2 & 2
\end{array}\right] .
$$

Step 2: $\mathrm{W}=\left(\mathrm{w}_{1}, \ldots, \mathrm{w}_{\mathrm{n}}\right)$ weights are $\mathrm{W}=(0,0,0.257$, $0.285,0.285,0.171,0)$

Step 3: The set of points $\mathrm{S}=\left\{\left(\mathrm{i} / \mathrm{n}, \sum_{\mathrm{j} f \mathrm{i}} \mathrm{w}_{\mathrm{j}}\right) \mathrm{li}=1, \ldots, \mathrm{n}\right\} \mathrm{E}\{(0,0)\}$ for the interpolation function is calculated as

$\mathrm{i}=1,\left(\frac{1}{7}, \mathrm{w}_{1}\right)=\left(\frac{1}{7}, 0\right)$

$\mathrm{i}=2,\left(\frac{2}{7}, \mathrm{w}_{1}+\mathrm{w}_{2}\right)=\left(\frac{2}{7}, 0\right)$

$\mathrm{i}=3,\left(\frac{3}{7}, \mathrm{w}_{1}+\mathrm{w}_{2}+\mathrm{w}_{3}\right)=\left(\frac{3}{7}, 0.257\right)$

$\mathrm{i}=7,\left(\frac{7}{7}, \mathrm{w}_{1}+\mathrm{w}_{2}+\mathrm{w}_{3}+\ldots+\mathrm{w}_{7}\right)=\left(\frac{7}{7}, 1\right)=(1,1)$

Based on these points the interpolation function is $\mathrm{w}^{*}$ is calculated using the algorithm used by Torra $^{[26,}{ }^{27]}$. Next, we calculate the set of WOWA weights $\omega=\left(\omega_{1}, \ldots, \omega_{n}\right)$ as follows:

$\mathrm{i}=1, \omega_{1}=\mathrm{w}^{*}\left(\mathrm{p}_{1}\right)=\mathrm{w}^{*}(0.2)$

$\mathrm{i}=7, \omega_{7}=\mathrm{w}^{*}\left(\sum_{\mathrm{i}=1}^{7} \mathrm{p}_{\mathrm{i}}\right)-\mathrm{w} *\left(\sum_{\mathrm{i}=1}^{6} \mathrm{p}_{\mathrm{i}}\right)$

WOWA weights are thus $\omega=\{0,0.2032,0.1926$, $0.1994,0.1994,0.1995,0\}$.

Step 4: Next WOWA values are calculated as $\phi_{\text {WowA }}\left(p_{1}, \ldots, p_{n}\right)=\sum_{i=1}^{n} \omega_{i} \times p_{\sigma(i)}$. For example for the first criterion we have

$$
\begin{aligned}
& \phi_{\text {WOWA }}(5,5,5,4,4,4,4)=0 * 5+0.2032 * 5 \\
& +0.01962 * 5+0.1994 * 4+0.1995 * 4 \\
& +0.1995 * 4+0 * 4=4.3915
\end{aligned}
$$

Aggregation result for the set of criteria is the following:

$$
\left[\mathrm{g}_{i}\right]=\left[\begin{array}{l}
4.3915 \\
1.8159 \\
4.1919 \\
3.9957 \\
3.7595 \\
4.3915 \\
4.9376 \\
1.8159
\end{array}\right],
$$


while results using OWA and Weighted mean are

$$
\left[\mathrm{g}_{i j}\right]=\left[\begin{array}{c}
4.249 \\
1.825 \\
4.077 \\
4.077 \\
3.82 \\
4.534 \\
4.99 \\
1.825
\end{array}\right] \text { and }\left[\mathrm{g}_{i \mathrm{j}}\right]=\left[\begin{array}{c}
4.5 \\
2.2 \\
4.2 \\
4.1 \\
3.8 \\
4.5 \\
4.8 \\
2.0
\end{array}\right] \text { respectively. }
$$

Acceptance result for criteria $\mathrm{g}_{2}$ and $\mathrm{g}_{8}$ are relative low and thus are excluded from problem We follow the same procedure for categories.

Members' $m_{j}$ preferences on criteria weights $w_{i}$ are expressed on numeric values as:

$$
\left[\mathrm{w}_{\mathrm{ij}}\right]=\left[\begin{array}{ccccccc}
18 & 15 & 14 & 15 & 16 & 19 & 20 \\
28 & 33 & 26 & 30 & 25 & 23 & 21 \\
7 & 5 & 9 & 8 & 10 & 9 & 11 \\
15 & 12 & 13 & 12 & 16 & 16 & 12 \\
11 & 9 & 14 & 8 & 5 & 9 & 6 \\
21 & 26 & 24 & 27 & 28 & 6 & 30
\end{array}\right]
$$

Aggregation results are depicted in the table below, compared to results from alternative aggregation approaches.

Table 1: Comparison of Aggregation approaches

\begin{tabular}{lcrc}
\hline OWA & Weighted mean & WOWA & Arithmetic mean \\
\hline 16.055 & 16.900 & 16.417 & 17 \\
27.717 & 27.000 & 26.030 & 27 \\
8.370 & 8.000 & 7.894 & 8 \\
13.055 & 13.890 & 13.417 & 14 \\
8.199 & 9.100 & 8.732 & 9 \\
25.343 & 25.100 & 24.659 & 26 \\
\hline
\end{tabular}

The above steps are followed for every set of parameters: criteria, actions scores, categories thresholds as well as indifference, preference and veto thresholds. Aggregated actions scores, criteria weights and categories thresholds, is the input parameter set for the multicriteria classification algorithm, which is applied next.

The above methodology has been applied to real world problems with sufficient results. An indicative problem that has been resolved refers to classification of locations for potential ATM installation into appropriate categories at the environment of a Greek bank. In brief, the bank wanted to classify locations for potential ATM installation in order to decrease failed installation costs as well as relocations. The bank's objective was to create a pool of potential viable sites for further consideration, excluding less viable ones. Thus, we formulated a decision problem for the classification of locations to appropriate non-ordered categories. Following a brainstorming technique, stakeholders from bank's divisions defined an initial set of parameters and assigned the supervision and operation of the entire decision procedure as well as the group coordination to a group facilitator. Group members were selected from several bank's divisions, resulting to a group of nine decision makers. Next, applying the methodology following all the steps, we received result sets with very high degree of accuracy compared to training sets, as well as high acceptance degree from group members.

\section{CONCLUSION}

In this study we presented a methodology for classification decisions where aggregation of members' preferences is executed at the parameter level. We presented details of the aggregation methodology as well as a sample application for a classification problem demonstrating its usage for similar problems.

Application of methodology in business environment and empirical findings provide evidence that the methodology is a valid approach for similar decision problems. In addition, we believe that the methodology can be easily applied to support group decisions in a variety of environments. However, since the methodology requires a relative substantial number of parameters, it is possible that group members who are not familiar enough with the methodology will be confused. Thus, the number of criteria and parameters should be kept to a number, which will minimize complexity without however loosing critical problem parameters. Concluding, we believe that this approach can be easily deployed to support group decisions in similar environments.

\section{REFERENCES}

1. Bui, T.X., 1987. Co-oP: A group decision support system for cooperative multiple criteria group decision making. Lecture Notes in Computer Science, No. 290. Springer, Berlin.

2. Calvo, T., R. Mesiar and R.R. Yager, 2004. Quantitative weights and aggregation. IEEE Trans. Fuzzy Syst., 12(1): 62-69.

3. Carlsson, C., D. Ehrenberg, P. Eklund, M. Fedrizzi, P. Gustafsson, P. Lindholm, G. Merkuryeva, T. Riisanen and A.G.S. Ventre, 1992. Consensus in distributed soft environments. Eur. J. Operat. Res., 61: 165-185. 
4. Cil, I., O. Alpturk and H.R. Yazgan, 2005. A new collaborative system framework based on a multiple perspective approach: InteliTeam. Decision Support Syst., 39: 619-641.

5. Colson, G. and B. Mareschal, 1994. JUDGES: A descriptive group decision support system for the ranking of the items. Decision Support Syst., 12: 391-404.

6. Dubois, D. and H. Prade, 1985. A review of fuzzy sets aggregation connectives. Inform. Sci., 36: 85-121.

7. Dubois, D. and J.L. Koning, 1991. Social choice axioms for fuzzy set aggregation. Fuzzy Sets Syst., 43: 257-274.

8. Espinasse, B. and T. Pauner, 1995. NegocIAD: A multi-criteria and multi-agent system for negotiation support. International Workshop on the Design of Cooperative Systems. INRIA, AntibesJuan-les-Pins, France.

9. Fodor, J.C. and M. Roubens, 1992. Aggregation and scoring procedures in multicriteria decisionmaking methods. Proceedings of the IEEE International Conference on Fuzzy Systems, San Diego, pp: 1261-1267.

10. Fodor, J.C. and M. Roubens, 1994. Fuzzy Preference Modelling and Multicriteria Decision Support. Theory and Decision Library, Series D, system Theory, Knowledge Engineering and Problem Solving, Vol. 14, Kluwer, Dordrecht.

11. Fodor, J.C., J.L. Marichal and M. Roubens, 1995. Characterization of the ordered weighted averaging operators. IEEE Trans. Fuzzy Syst., 3(2): 236-240.

12. Geldermann, J., K.J. Zhang and O. Rentz, 2003. Multi-criteria group decision support for integrated technique assessment. 57th Meeting of the European Working Group Multiple Criteria Decision Aiding Viterbo.

13. Herrera, F., E. Herrera-Viedma and J.L. Verdegay, 1996. Direct approach processes in group decision making using linguistic OWA operators. Fuzzy Sets Syst., 79: 175-190.

14. Jarke, M., M.T. Jelassi and M.F. Shakun, 1987. MEDIATOR: Toward a negotiation support system. Eur. J. Operat. Res., 31(3): 314-334.

15. Kacprzyk, J., 1986. Group decision making with a fuzzy linguistic majority. Fuzzy Sets Syst., 18: $105-118$.

16. Kim, J.K. and Sang Hyun Choi, 2001. A utility range-based interactive group support system for multiattribute decision making. Comput. Operat. Res., 28: 485-503.

17. Lewandowski, A., 1989. SCDAS-decision support system for group decision making: Decision theoretic framework. Decision Support Systems, 5(4): 403-423.

18. Lu, J., M.A. Quaddus, K.L. Poh and R. Williams, 1999. The Design of a Knowledge-Based Guidance System for an Intelligent Multiple Objective Decision Support System (IMODSS). Proceedings of the 10th Australasian Conference on Information Systems.
19. Marques, P. and R.A. Ribeiro, 2003. Aggregation with generalized mixture operators using weighting functions. Fuzzy Sets Syst., 137(1): 43-58.

20. Matsatsinis, N.F. and A.R. Samaras, 2001. MCDA and preference disaggregation in group decision support systems. Eur. J. Operat. Res., 130: 414-429.

21. Noori, H., 1995. The design of an integrated group decision support system for technology assessment. $\mathrm{R}$ and D Manage., 25(3): 309-322.

22. Nunamaker, J.F., A.R. Dennis, J.S. Valacich, D.R. Vogel and J.F. George, 1991. Electronic meeting systems to support group work. Commun. ACM., 34 (7): 40-60.

23. Pongpeng, J. and J. Liston, 2003. TenSeM: A multicriteria and multidecision-makers' model in tender evaluation. Construct. Manage. Econ., 21: 21-30.

24. Quaddus, M.A., D.J. Atkinson and M. Levy, 1992. An application of decision conferencing to strategic planning for a voluntary organization. Interfaces, 22(6): 61-71.

25. Teckle, A., P. Bijaya and L. Shrestna Duckstein, L., 1998. A Multiobjective Decision Support System for Multiresource Forest Management. Group Decision and Negotiation, 7: 23-40.

26. Torra, V., 1997. The Weighted OWA operator. Int. J. Intel. Syst., 12: 153-166.

27. Torra, V., 2000. The WOWA operator and the interpolation function $\mathrm{W}^{*}$ : Chen and Otto's interpolation method revisited. Fuzzy Sets Syst., 113 (3): 389-396.

28. Vetchera, R., 1994. GDSS-X: An experimental group decision support system for program planning. In: Climaco, J. (Ed.), Multicriteria Analysis, Proceedings of the XIth International Conference on MCDM, 1-6 August 1994, Springer, Berlin.

29. Yager, R.R., 1988. On ordered weighted averaging aggregation operators in multicriteria decision making. IEEE Trans. Syst. Man Cybernet, 18: 183-190.

30. Yager, R.R., 1993. Families of OWA operators. Fuzzy Sets Syst., 59: 125-148.

31. Yager, R.R., 1993a. Fuzzy Screaning Systems. In: Lowen, R. and M. Roubens (Eds.), Fuzzy Logic: State of the Art, Kluwer, Dordrecht, pp: 251-261.

32. Yager, R.R., 1994. Aggregation operators and fuzzy systems modelling. Fuzzy Sets Syst., 67: 129-145.

33. Yager, R.R. and A. Rybalov, 1996. Uninorm aggregation operators. Fuzzy Sets Syst., 80: 111-120.

34. Zadeh, L.A., 1983. A computational approach to fuzzy quantifiers in natural languages. Comput. Math. Applied, 9: 149-184. 